\title{
Fifty Tumor Necrosis Factor-Based Isolated Limb Perfusions for Limb Salvage in Patients Older Than 75 Years With Limb- Threatening Soft Tissue Sarcomas and Other Extremity Tumors
}

\author{
Boudewijn van Etten, MD, Albertus N. van Geel, MD, PhD, Johannes H. W. de Wilt, MD, PhD, \\ and Alexander M. M. Eggermont, MD, PhD
}

\begin{abstract}
Background: Isolated limb perfusion (ILP) with tumor necrosis factor (TNF) and melphalan is highly effective in treating limb-threatening soft tissue sarcoma (STS) and other bulky tumors. Because of fear of TNF-associated toxicity, ILP with TNF is not offered to older patients in some cancer centers, although especially in older patients, every attempt to avoid an amputation that may end their independence must be considered.

Methods: Out of 306 TNF-based ILPs, 50 ILPs were performed for limb salvage in 43 patients $>75$ years old (range, 75-91 years): 29 STS and 14 melanoma patients.

Results: In the STS patients, a response rate of $76 \%$ and a limb-salvage rate of $76 \%$ were achieved; in the melanoma patients, a $100 \%$ response rate and a $93 \%$ limb-salvage rate were achieved. Local toxicity was mild. The three postoperative deaths that occurred in the total series of 306 TNF-based ILPs in Rotterdam $(<1 \%)$ occurred in patients $>75$ years old after leakage-free perfusions and were not related to TNF but to extremely high-risk profiles in these three patients.

Conclusions: Older patients should not be withheld a TNF-based ILP for limb salvage, because the procedure is safe and highly effective in these patients.
\end{abstract}

Isolated limb perfusion (ILP) is a technique of cancer treatment that delivers high doses of cytostatic drugs to a tumor-bearing extremity that is isolated from the systemic circulation and connected to a heart-lung machine. ${ }^{1}$ By ILP, regional concentrations of chemotherapeutic agents 15 to 20 times higher than those reached after systemic administration can be achieved without systemic toxicity. ${ }^{2}$ In the management of locally advanced soft tissue sarcoma (STS), limb salvage is a major challenge. In patients with multiple and/or bulky in-transit melanoma metastases, obtaining local control is a major challenge. In contrast to the inefficacy of ILP

Received March 14, 2002; accepted August 21, 2002.

From the Department of Surgical Oncology, University Hospital Rotterdam-Daniel den Hoed Cancer Center, Rotterdam, The Netherlands.

Address correspondence and reprint requests to: Alexander M. M. Eggermont, MD, PhD, Department of Surgical Oncology, University Hospital Rotterdam-Daniel den Hoed Cancer Center, P.O. Box 5201, 3008 AE Rotterdam, The Netherlands; Fax: 31-10-439-1011; E-mail: eggermont@chih.azr.nl.

Published by Lippincott Williams \& Wilkins @ 2003 The Society of Surgical Oncology, Inc. with melphalan alone in the management of irresectable extremity STS, with response rates of only $10 \%$ to $35 \%, 3,4$ the introduction of tumor necrosis factor- $\alpha$ (TNF) in combination with melphalan in ILP has been reported in a European multicenter trial; it resulted in response rates $>80 \%$ and limb-salvage rates $>70 \%$ in STS. ${ }^{5,6}$ These results led to the approval of TNF in Europe. ${ }^{7}$ Also, in the management of in-transit metastases, TNF seems to improve complete response (CR) rates, ${ }^{8}$ especially in patients with bulky tumors and in patients whose previous ILP with melphalan alone failed, as has been demonstrated by reports from the Surgery Branch of the National Cancer Institute in the United States. ${ }^{9,10}$

The incidence of STS increases rapidly above the age of 50 years. Approximately $18 \%$ of the patient population is above the age of 70 years. ${ }^{4}$ The incidence of malignant melanoma has more than doubled over the last 20 years. ${ }^{12}$ For both men and women, rates increased relatively more in the older age groups. As a consequence of these epidemiological features, we are confronted with a large group of elderly patients who might need a limb-saving procedure such as ILP. These pa- 
tients, especially, will be severely limited in their mobility and lose independence when amputation of a limb has to be performed. Therefore, especially in the elderly, every attempt to avoid amputation must be considered, and a TNF-based ILP must be considered despite the age of the patients. The perception that TNF-based ILP is a risky endeavor has been demonstrated to be false provided that leakage is monitored and well controlled. ${ }^{13}$ But even in the event of significant leakage, we have demonstrated that with correct fluid management and postoperative care, patients do not develop major or life-threatening complications. ${ }^{14}$ Therefore we do not think it is reasonable to consider age a limiting factor for patients to undergo a TNF-based ILP. Here we present our single Rotterdam institution experience in a large series of patients aged $>75$ years with irresectable STS or in-transit melanoma metastases of an extremity. These patients were all treated by ILP with high-dose TNF and melphalan.

\section{PATIENTS AND METHODS}

\section{ILP Methodology}

We have described the procedure of the current TNFbased ILP previously. ${ }^{1,2}$ In brief, isolation of the blood circuit of a limb is achieved by clamping and cannulating the major artery and vein, connecting to an oxygenated extracorporeal circuit, ligating collateral vessels, and applying a tourniquet. Once isolation is secured, drugs can be injected into the perfusion circuit.

\section{Drugs}

Recombinant human TNF- $\alpha\left(4.9-5.8 \times 10^{7} \mathrm{U} / \mathrm{mg}\right)$ was administered at doses of 2 to $4 \mathrm{mg}$ in the perfusion circuit; recombinant human interferon- $\gamma$ (IFN $\gamma ; .2 \mathrm{mg}$ or $1.5 \times 10^{6}$ U/ampoule) was administered in the ILPs performed in the period 1991 to 1993 on days -2 and -1 subcutaneously and on day 0 into the perfusion circuit. Both TNF and IFN $\gamma$ were obtained from Boehringer Ingelheim $\mathrm{GmbH}$ (Ingelheim/Rhein, Germany). Melphalan (L-phenylalanine mustard; Alkeran ${ }^{\mathrm{TM}}$; Burroughs Wellcome, London, UK) was obtained as a sterile powder $(100 \mathrm{mg})$ that was dissolved aseptically by using solvent and diluent provided by Burroughs Wellcome (London, UK). Because of its efficacy and low regional toxicity profile, melphalan is the standard drug, most commonly used at a dose of $10 \mathrm{mg} / \mathrm{L}$ of perfused tissue for a leg and $13 \mathrm{mg} / \mathrm{L}$ for an arm. The perfusate is heated to $39^{\circ} \mathrm{C}$ to $40^{\circ} \mathrm{C}$ to achieve mild hyperthermia tissue temperatures in the limbs, to be kept stable at $39^{\circ} \mathrm{C}$. Radiolabeled albumen is injected into the extracorporeal circuit so that leakage into the systemic circulation can be detected with a precordial scintillation probe. ${ }^{15}$ Leakage monitoring is mandatory, especially now that high doses of TNF are used in the treatment of STS and melanomas. After 1.5 hours of perfusion, the limb is rinsed with an electrolyte solution, cannulas are removed, and the vessels are repaired. Classification of postoperative limb toxicity was performed according to Wieberdink et al. ${ }^{16}$ : grade I, no reaction; grade II, slight erythema, edema, or both; grade III, considerable erythema and/or edema with some blistering, slightly disturbed motility permissible; grade IV, extensive epidermolysis and/or obvious damage to the deep tissues, causing definite functional disturbances; threatening or manifest compartmental syndrome; and grade $\mathrm{V}$, reaction that may necessitate amputation.

\section{Patients}

At the Erasmus University Medical Center-Daniel den Hoed Cancer Center, 306 TNF-based ILPs were performed in STS patients (224 ILPs) and melanoma patients (82 ILPs) between 1991 and 2001. In 43 patients (14 men and 29 women) older than 75 years, 50 TNFbased ILPs were performed. Twelve patients also received $.2 \mathrm{mg}$ of IFN $\gamma$ subcutaneously on the 2 days before the ILP as well as $.2 \mathrm{mg}$ of IFN $\gamma$ in the perfusion circuit during ILP. All ILP and follow-up data in our institution are recorded prospectively in a database. Patient and ILP characteristics, treatment results, and follow-up data are listed in Table 1 for STS or other nonmelanoma limb-threatening tumors and in Table 2 for melanoma. The mean age of this selected group of patients was 79 years (range, 75-91 years). Twenty-nine patients with irresectable STS or other limb-threatening tumors of the leg $(n=19)$ or arm $(n=10)$ underwent 34 ILPs (Table 1). Nineteen were treated for primary tumors and 10 for recurrences. In this group, the median size of single tumors $(\mathrm{n}=20)$ was $10 \mathrm{~cm}$ (range, $6-38 \mathrm{~cm})$, and for multifocal tumors $(\mathrm{n}=9)$ it was $5 \mathrm{~cm}$ (range, 1-20 $\mathrm{cm}$ ). Two patients with Stewart-Treves syndrome had undergone three ILPs each. One patient underwent two perfusions. Fourteen patients with in-transit melanoma metastases (all lower extremity) underwent 16 ILPs (Table 2). Two patients underwent two ILPs.

\section{RESULTS}

\section{Sarcomas and Nonmelanoma Limb-Threatening Tumors}

In the STS group, all patients but two (postoperative deaths) were evaluated for response by magnetic resonance imaging (MRI) and histopathologic evaluation of the tumor resection specimen after response to the ILP. 
TABLE 1. Characteristics of 29 patients with irresectable STS or other limb-threatening tumors at the time of ILP $(n=34)$ with TNF and melphalan

\begin{tabular}{|c|c|c|c|c|c|c|c|c|c|c|c|c|c|c|c|}
\hline $\begin{array}{l}\text { Patient } \\
\text { No. }\end{array}$ & Sex & $\begin{array}{l}\text { Age } \\
\text { (y) }\end{array}$ & Histology & $\begin{array}{l}\text { Grade } \\
(1-3)\end{array}$ & Site & $\begin{array}{l}\text { No. } \\
\text { Tumors }\end{array}$ & $\mathrm{P} / \mathrm{R}$ & $\begin{array}{l}\text { Type } \\
\text { of ILP }\end{array}$ & $\begin{array}{c}\text { Local toxicity } \\
\text { (Wieberdink) (I-V) }\end{array}$ & $\begin{array}{l}\text { Clinical } \\
\text { response }\end{array}$ & $\begin{array}{l}\text { Histological } \\
\text { response } \\
\text { (\% necrosis) }\end{array}$ & $\begin{array}{c}\text { Final } \\
\text { outcome }\end{array}$ & $\begin{array}{l}\text { Limb } \\
\text { salvage }\end{array}$ & $\begin{array}{c}\text { Dead (D) } \\
\text { or alive (A) }\end{array}$ & $\begin{array}{l}\text { Follow-up } \\
\text { (mo) }\end{array}$ \\
\hline \multirow[t]{3}{*}{$1^{a}$} & $\mathrm{~F}$ & 78 & Angiosarcoma & 2 & Lo arm & $>100$ & $\mathrm{R}$ & Brach & 2 & $\mathrm{CR}$ & ND & $\mathrm{CR}$ & & & \\
\hline & $\mathrm{F}$ & 80 & Angiosarcoma & 2 & Lo arm & $>100$ & $\mathrm{RR}$ & Axil & 2 & $\mathrm{CR}$ & ND & $\mathrm{CR}$ & & & \\
\hline & $\mathrm{F}$ & 82 & Angiosarcoma & 2 & Lo arm & $>100$ & $\mathrm{RR}$ & Axil & 3 & PR & ND & PR & $\mathrm{Y}$ & $\mathrm{D}$ & 47 \\
\hline 2 & $\mathrm{~F}$ & 75 & Liposarcoma & 1 & Lo arm & 1 & $\mathrm{R}$ & Brach & 3 & $\mathrm{CR}$ & ND & $\mathrm{CR}$ & $\mathrm{Y}$ & A & $\geq 85$ \\
\hline 3 & $\mathrm{~F}$ & 82 & Leiomyosarcoma & 2 & Up arm & 1 & $\mathrm{P}$ & Brach & 2 & PR & $>70$ & PR & $\mathrm{Y}$ & D & 57 \\
\hline 4 & $\mathrm{~F}$ & 82 & Mal Fibr Hist & 3 & Up leg & 1 & $\mathrm{P}$ & Iliac & 3 & $\mathrm{NC}$ & ND & $\mathrm{NC}$ & $\mathrm{Y}$ & $\mathrm{D}$ & 6 \\
\hline 5 & $\mathrm{~F}$ & 83 & Liposarcoma & 3 & Up leg & 2 & $\mathrm{P}$ & Iliac & 2 & PR & $>90$ & PR & $\mathrm{Y}$ & A & $\geq 55$ \\
\hline \multirow[t]{2}{*}{$6^{a}$} & $\mathrm{~F}$ & 81 & Mal Fibr Hist & 2 & Lo leg & 4 & $\mathrm{R}$ & Popl & 2 & $\mathrm{NC}$ & ND & $\mathrm{NC}$ & & & \\
\hline & $\mathrm{F}$ & 82 & Mal Fibr Hist & 2 & Lo leg & 6 & $\mathrm{RR}$ & Fem & 2 & $\mathrm{CR}$ & ND & $\mathrm{CR}$ & $\mathrm{N}$ & $\mathrm{D}$ & 22 \\
\hline 7 & $\mathrm{~F}$ & 78 & Pleiomorfsarc & 3 & Fos popl & 1 & $\mathrm{R}$ & Iliac & 2 & $\mathrm{NC}$ & ND & $\mathrm{NC}$ & $\mathrm{N}$ & $\mathrm{D}$ & 14 \\
\hline $8^{b}$ & M & 91 & Liposarcoma & 3 & Fos popl & 1 & $\mathrm{P}$ & Iliac & 2 & ND & ND & ND & $\mathrm{Y}$ & D & 0 \\
\hline 9 & $\mathrm{~F}$ & 87 & Leiomyosarcoma & 2 & Foot & 1 & $\mathrm{R}$ & Popl & 2 & $\mathrm{NC}$ & ND & $\mathrm{NC}$ & $\mathrm{Y}$ & $\mathrm{D}$ & 8 \\
\hline 10 & M & 76 & Leiomyosarcoma & 3 & Lo arm & 1 & $\mathrm{P}$ & Brach & 4 & PR & 90 & PR & $\mathrm{Y}$ & A & $\geq 43$ \\
\hline 11 & M & 75 & Clear cell tumor & 3 & Up + lo leg & 3 & $\mathrm{R}$ & Iliac & 3 & $\mathrm{CR}$ & 100 & $\mathrm{CR}$ & $\mathrm{Y}$ & D & 9 \\
\hline 12 & $\mathrm{~F}$ & 75 & Mal Fibr Hist & 2 & Lo foot & 1 & $\mathrm{R}$ & Fem & 3 & $\mathrm{NC}$ & $>90$ & PR & $\mathrm{Y}$ & $\mathrm{D}$ & 3 \\
\hline 13 & M & 83 & $\begin{array}{l}\text { Extraskeletal } \\
\text { osteosarcoma }\end{array}$ & 3 & Up leg & 1 & $\mathrm{P}$ & Iliac & 3 & $\mathrm{NC}$ & 90 & PR & $\mathrm{Y}$ & $\mathrm{D}$ & 9 \\
\hline $14^{b}$ & M & 76 & Squamous cell & NA & Lo arm & 3 & $\mathrm{R}$ & Axil & 4 & ND & ND & ND & $\mathrm{Y}$ & $\mathrm{D}$ & 0 \\
\hline 15 & $\mathrm{~F}$ & 77 & Leiomyosarcoma & 3 & Fos popl & 1 & $\mathrm{P}$ & Popl & 2 & PR & 90 & PR & $\mathrm{Y}$ & A & 239 \\
\hline \multirow[t]{3}{*}{$16^{a}$} & $\mathrm{~F}$ & 77 & Angiosarcoma & 2 & Lo Arm & 30 & $\mathrm{P}$ & Brach & 3 & $\mathrm{CR}$ & ND & $\mathrm{CR}$ & & & \\
\hline & $\mathrm{F}$ & 78 & Angiosarcoma & 2 & $\mathrm{Up}+$ lo arm & 20 & $\mathrm{R}$ & Axil & 2 & $\mathrm{CR}$ & ND & $\mathrm{CR}$ & & & \\
\hline & $\mathrm{F}$ & 80 & Angiosarcoma & 2 & $\mathrm{Up}+$ lo arm & $>10$ & $\mathrm{RR}$ & Axil & 1 & $\mathrm{CR}$ & ND & $\mathrm{CR}$ & $\mathrm{Y}$ & A & $\geq 46$ \\
\hline 17 & $\mathrm{~F}$ & 83 & Mal Fibr Hist & 3 & Lo leg & 3 & $\mathrm{R}$ & Popl & 2 & PR & $<50$ & PR & $\mathrm{N}$ & D & 26 \\
\hline 18 & $\mathrm{~F}$ & 76 & Angiosarcoma & 1 & Lo arm & 21 & $\mathrm{P}$ & Brach & 3 & $\mathrm{CR}$ & 100 & $\mathrm{CR}$ & $\mathrm{Y}$ & A & $\geq 21$ \\
\hline 19 & M & 83 & Synoviosarcoma & 2 & Up leg & 1 & $\mathrm{R}$ & Iliac & 2 & $\mathrm{CR}$ & ND & $\mathrm{CR}$ & $\mathrm{N}$ & A & $\geq 28$ \\
\hline 20 & $\mathrm{~F}$ & 76 & Schwannoma & 3 & Up leg & 1 & $\mathrm{P}$ & Iliac & - & $\mathrm{NC}$ & $<50$ & $\mathrm{NC}$ & $\mathrm{Y}$ & A & $\geq 26$ \\
\hline 21 & M & 79 & Schwannoma & 3 & Lo arm & 1 & $\mathrm{P}$ & Brach & 2 & PR & $<10$ & PR & $\mathrm{Y}$ & A & $\geq 10$ \\
\hline 22 & $\mathrm{~F}$ & 77 & Kapos sarcoma & 1 & Lo leg & 30 & $\mathrm{P}$ & Fem & 1 & $\mathrm{CR}$ & 100 & $\mathrm{CR}$ & $\mathrm{N}$ & A & $\geq 18$ \\
\hline 23 & $\mathrm{M}$ & 81 & Mal Fibr Hist & 3 & Lo arm & 1 & $\mathrm{P}$ & Brach & 1 & $\mathrm{NC}$ & $<50$ & $\mathrm{NC}$ & $\mathrm{Y}$ & A & $\geq 17$ \\
\hline $24^{b}$ & M & 76 & $\begin{array}{l}\text { Undifferentiated } \\
\text { carcinoma }\end{array}$ & 2 & Up leg & 1 & $\mathrm{P}$ & Iliac & 2 & $\mathrm{CR}$ & 100 & $\mathrm{CR}$ & $\mathrm{N}$ & $\mathrm{D}$ & 0 \\
\hline 25 & M & 75 & Liposarcoma & 3 & Fos popl & 1 & $\mathrm{P}$ & Iliac & 2 & $\mathrm{NC}$ & $>50$ & PR & $\mathrm{N}$ & A & $\geq 11$ \\
\hline 26 & M & 81 & Epitheloid sarcoma & 3 & Lo leg & 1 & $P$ & Fem & 1 & PR & $>90$ & PR & $\mathrm{Y}$ & A & $\geq 8$ \\
\hline 27 & $\mathrm{~F}$ & 78 & Angiosarcoma & 1 & Total arm & $>20$ & $\mathrm{P}$ & Axil & 2 & $\mathrm{CR}$ & ND & $\mathrm{CR}$ & $\mathrm{Y}$ & A & $\geq 6$ \\
\hline 28 & $\mathrm{M}$ & 80 & Squamous cell & NA & Hand & 1 & $\mathrm{P}$ & Brach & 2 & PR & ND & PR & $\mathrm{Y}$ & A & $\geq 3$ \\
\hline 29 & M & 86 & Mal Fibr Hist & 3 & Lo leg & 1 & $\mathrm{P}$ & Fem & 2 & PR & ND & PR & $\mathrm{Y}$ & $\mathrm{A}$ & $\geq 3$ \\
\hline Mean & & 79.5 & & & & & & & & & & CR $38 \%$ & $22 / 29=76 \%$ & & 26.0 \\
\hline Median & & 78 & & & & & & & & & & PR 38\% & & & 18.0 \\
\hline
\end{tabular}

Up arm, upper arm; Lo arm, lower arm; Up leg, upper leg; Lo leg, lower leg; Fos Popl, fossa poplitea; Fem, femoral ILP; Popl, popliteal ILP; Axil, axilar ILP; Brach, brachial ILP; P, primary; R, recurrence; RR, re-recurrence; CR, complete response; PR, partial response; NC, no change; NA, not applicable; ND, not determined; ILP, isolated limb perfusion; Mal Fibr Hist, malignant fibrous histiocytoma. Overall Response rate is $76 \%$ (CR 38\%, PR $38 \%)$.

${ }^{a}$ These have undergone multiple perfusions.

${ }^{b}$ Patient died after surgery.

CRs were defined as clinical MRI-proven CRs, which were not operated on a second time, and clinical MRIproven partial responses (PRs) that, after resection, were demonstrated to be $100 \%$ necrotic and were classified as histopathologic CRs. PRs were defined as tumors that underwent shrinkage of $>50 \%$ or, in case of $<50 \%$ clinical shrinkage, revealed a $>50 \%$ necrosis on resection. The overall response rate (CR plus PR) was 76\%, consisting of $38 \% \mathrm{CR}$ and $38 \%$ PR. No change, defined as $<50 \%$ tumor shrinkage and $<50 \%$ necrosis, was seen in $18 \%$ of the patients. None of the patients had disease progression within 3 months of the ILP (Table 1).
In the soft tissue patient population, $31 \%$ of patients had multiple sarcomas and were not candidates for resections after ILP. In the patients with a single sarcoma, resection was made possible by the induction treatment with ILP and was performed in 16 of 20 patients at a median of 2.5 months after ILP. ILP and surgical treatment resulted in limb salvage in $22(76 \%)$ of 29 patients after a median follow-up of 18 months. Amputation was performed in 7 of 29 patients. In three patients (all with multiple sarcomas in the extremity), repeated ILP was performed after a median of 20 months (range, 13-24 months) after prior ILP. In the sarcoma group, despite 
TABLE 2. Characteristics of 14 patients with in-transit melanoma metastases at the time of ILP $(n=16)$ with TNF and melphalan

\begin{tabular}{|c|c|c|c|c|c|c|c|c|c|}
\hline $\begin{array}{l}\text { Patient } \\
\text { No. }\end{array}$ & Sex & $\begin{array}{l}\text { Age } \\
(y)\end{array}$ & Site & $\begin{array}{l}\text { No. } \\
\text { Tumor }\end{array}$ & $\begin{array}{l}\text { Type of } \\
\text { ILP }\end{array}$ & $\begin{array}{c}\text { Local toxicity } \\
\text { (Wieberdink) }(\mathrm{I}-\mathrm{V})\end{array}$ & $\begin{array}{c}\text { Final } \\
\text { outcome }\end{array}$ & $\begin{array}{c}\text { Dead }(\mathrm{D}) \\
\text { or alive }(\mathrm{A})\end{array}$ & $\begin{array}{l}\text { Follow-up } \\
\text { (mo) }\end{array}$ \\
\hline \multirow[t]{2}{*}{$1^{a}$} & $\mathrm{~F}$ & 78 & Lo leg & $>20$ & Fem & 2 & $\mathrm{CR}$ & & \\
\hline & $\mathrm{F}$ & 80 & Tot leg & $>100$ & Iliac & 2 & $\mathrm{CR}$ & A & $\geq 132$ \\
\hline 2 & $\mathrm{~F}$ & 76 & Tot leg & $>100$ & Iliac & 2 & CR & $\mathrm{D}$ & 10 \\
\hline 3 & $\mathrm{~F}$ & 75 & Lo leg & $>10$ & Popl & 3 & $\mathrm{CR}$ & D & 4 \\
\hline \multirow[t]{2}{*}{$4^{a b}$} & $\mathrm{~F}$ & 82 & Lo leg & $>20$ & Popl & 2 & PR & & \\
\hline & $\mathrm{F}$ & 83 & Lo leg & $>100$ & Iliac & 3 & $\mathrm{CR}$ & $\mathrm{D}$ & 44 \\
\hline 5 & $\mathrm{~F}$ & 77 & Lo leg & $>10$ & Iliac & 2 & PR & $\mathrm{D}$ & 11 \\
\hline 6 & $\mathrm{~F}$ & 76 & Tot leg & $>50$ & Iliac & 2 & CR & D & 45 \\
\hline 7 & $\mathrm{~F}$ & 75 & Lo leg & $>50$ & Iliac & 1 & CR & $\mathrm{D}$ & 21 \\
\hline 8 & $\mathrm{~F}$ & 76 & Lo leg & $<10$ & Popl & 2 & CR & $\mathrm{D}$ & 16 \\
\hline 9 & $\mathrm{~F}$ & 80 & Tot leg & $>10$ & Iliac & 2 & $\mathrm{CR}$ & A & $\geq 46$ \\
\hline 10 & $\mathrm{~F}$ & 78 & Lo leg & $>10$ & Fem & 2 & $\mathrm{CR}$ & A & $\geq 40$ \\
\hline 11 & $\mathrm{~F}$ & 79 & Foot & $>50$ & Fem & 2 & CR & A & $\geq 17$ \\
\hline 12 & $\mathrm{~F}$ & 82 & Lo leg & $>20$ & Fem & 3 & PR & A & $\geq 3$ \\
\hline 13 & $\mathrm{M}$ & 77 & Lo leg & $>20$ & Iliac & 3 & PR & A & $\geq 3$ \\
\hline 14 & $\mathrm{~F}$ & 91 & Lo leg & $>100$ & Fem & 2 & $\mathrm{CR}$ & A & $\geq 3$ \\
\hline Mean & & 78.7 & & & & & CR $75 \%$ & & 27.0 \\
\hline Median & & 78 & & & & & PR $25 \%$ & & 16 \\
\hline
\end{tabular}

Abbreviations: Lo leg, lower leg; tot leg, total leg; Fem, femoral ILP; Popl, popliteal ILP; CR, complete response; PR, partial response; ILP, isolated limb perfusion; TNF, tumor necrosis factor. Overall Response rate is $100 \%$ (CR 75\%, PR 25\%).

${ }^{a}$ Patients who have undergone multiple perfusions $(\mathrm{n}=2)$.

${ }^{b}$ This patient underwent an above-knee amputation of the limb because of arterioscelosis more than 1 year after the last perfusion.

multiple tumors being present in $31 \%$ of the sarcoma patient population, local recurrence-free survival at 2 years was $50 \%$. Despite the median age of 78 years, $50 \%$ of all patients were still alive at 4 years.

\section{Patients With Multiple or Bulky Melanoma In-Transit Metastases}

In the melanoma patients, an overall response rate of $100 \%$ was achieved; this consisted of $75 \%$ CR and $25 \%$ PR. Therefore, all patients responded, and no stable disease or disease progression was observed. This resulted in a 93\% limb salvage at a median follow-up of 16 months. The single amputation in this group (patient 4; Table 2) was not tumor related but was caused by severe arteriosclerosis more than 14 months after the last ILP. Two patients underwent a second perfusion 19 and 25 months after the first ILP. Both resulted in a CR after the repeated ILP. In the melanoma patients, no postoperative deaths occurred. Local progression-free survival in the melanoma population was almost 1 year. Despite the median age of 78 years, $33 \%$ of all patients were still alive at 5 years.

\section{Local Toxicity}

In $96 \%$ of the perfusions, only mild to moderate (Wieberdink grade I-III) local toxicity was observed. In none of the patients did an amputation have to be performed because of TNF- or melphalan-related toxicity after ILP. Only in the patient with a large ulcerating undifferentiated carcinoma metastasis in the upper leg, which became completely necrotic after the ILP and subsequently became infected, did a post-ILP amputation have to be undertaken, because the metastasis was the source of (eventually fatal) sepsis.

\section{Leakage Control and Systemic Toxicity}

\section{Leakage Control}

The median leakage rate was $0 \%$ (range, $0 \%-20 \%$ ) in the 50 ILPs described in this series. In the sarcoma group of 34 ILPs, there were 26 ILPs with $0 \%$ leakage, 5 with $<7 \%$ leakage, and 3 with significant leakage of $19 \%$, $20 \%$, and $20 \%$. In the melanoma group of 16 ILPs, there were 10 ILPs with $0 \%$ leakage and 3 with $<5 \%$ leakage. There were three ILPs with significant leakage of $10 \%$, $12 \%$, and $13 \%$. None of these six patients with $10 \%$ to $20 \%$ leakage experienced grade 3 or 4 hypotension or any other form of grade 3 or 4 toxicity.

\section{Systemic Toxicity}

Most patients went through a slightly hyperdynamic postoperative period, which usually lasted 2 to 6 hours, with slightly increased heart rates and temperatures as a reaction to the circulating TNF immediately after the ILP. No major toxicity was observed in the immediate postoperative phase in any of the 43 older patients. 
One patient with a history of multiple myocardial infarction and angina pectoris (patient 19; Table 1) developed a postoperative myocardial infarction. The ILP was associated with a leakage rate of $3 \%$, and the postoperative course was associated with grade 2 hypotension.

Except in the patient (patient 8; Table 1) who developed a thrombosis of the mesenteric artery 3 days after the ILP and in the patient (patient 24; Table 1) who developed septic shock because of infection of the massive necrosis of a large ulcerated tumor mass 10 days after the ILP, no grade 2, 3, or 4 toxicity was observed with respect to liver function, renal function, or shocklike symptoms. Temporary mild fever (World Health Organization grade II or III) occurred after 32 of the 50 perfusions.

\section{Complications}

In the total series of 306 TNF-based ILPs performed between 1991 and 2001 in the Daniel den Hoed Cancer Center, three patients died from postoperative complications. All three patients were $>75$ years old. Two patients with a high-risk cardiovascular status and history died because of cardiovascular complications: a 91-yearold patient (patient 8; Table 1) developed a thrombosis of the mesenteric artery 3 days after the ILP, with a fatal outcome. A 76-year-old patient (patient 14; Table 1) with a history of prior cerebrovascular accidents died from a massive cerebrovascular accident on day 3 after an uneventful and leakage-free ILP. A cardiovascular complication also occurred in an 83-year-old patient (patient 19; Table 1). This patient had a history of multiple myocardial infarctions and angina pectoris and developed a postoperative myocardial infarction after yet another well-controlled ILP with a leakage rate of $3 \%$ and no significant postoperative hypotension. The third patient who died in the postoperative phase (patient 24; Table 1) developed immediate and total necrosis of a very large ulcerating undifferentiated carcinoma metastasis in the upper leg. This necrotic mass became infected, and the patient developed septic shock. Despite an amputation and optimal medical management, the patient died of sepsis.

\section{DISCUSSION}

In elderly people, amputation of a limb has a major effect on their independence and daily activities. However, older patients with irresectable STS or recurrent melanoma of the extremities are often subjected to amputation because the risk of an ILP is considered to be too high. Here we demonstrated that ILP is very efficient in achieving limb salvage and local tumor control in elderly patients, with acceptable morbidity and mortality. In the face of imminent amputation or unacceptable loss of control over locoregional tumor growth in melanoma patients, we have not turned down any patient above the age of 75 years for a TNF-based ILP. Thus, we have accepted the considerable risk associated with this position. Here we report on the largest single-institution experience with the efficacy and risks of TNF-based ILP in elderly patients. Out of 306 TNF-based ILPs, 50 ILPs were performed in this patient population with the goal of avoiding amputation, which more than in any other age group determines the independence and quality of how these patients can continue their lives.

Until several years ago, TNF was thought be inapplicable in a clinical setting because of its severe toxicity when administered systemically. However, in an isolated perfusion setting, it can be used very safely and is extremely efficient in inducing tumor responses when combined with cytostatic agents. We have demonstrated that this extremely potent synergy is based on the selective vasodestruction of the tumor-associated vasculature, 5,17 as well as on the greatly enhanced uptake of melphalan or any other chemotherapeutic drug in the tumor when combined with TNF in the ILP setting. ${ }^{18,19}$

Safe administration of TNF is guaranteed because we use continuous leakage monitoring and adequate hydration of patients. These components are both essential in the management of possible TNF-related toxic side effects. ${ }^{10}$ The median leakage during ILP was $<0 \%$ (range, $0 \%-20 \%$ ). Even in cases with leakage, this can be managed very well. We previously described a series of patients with leakage from $12 \%$ to $65 \%$. No fatal complications occurred, and only a few shocks were observed, which could be managed without intubation and with little need for vasopressor support. ${ }^{11}$ Also in case of leakage, adequate hydration turned out to be the key in the treatment of TNF-related toxicity.

Also, in this group of older patients, ILP can be performed safely, without severe toxicity and morbidity. In this patient group, with a mean age of 79 years, the overall perioperative mortality was low, and the local toxicity was Wieberdink grade II or III in the vast majority of patients. Vrouenraets et al. ${ }^{20}$ recently reported on regional toxicity after ILP with TNF and demonstrated that increasing age was not correlated with more severe toxicity. The median hospital stay in this patient population of elderly patients after ILP was approximately 2 weeks. In the postoperative period, most patients were completely mobilized and left the hospital without severe functional impairment. 
The response rates and limb salvage percentages were comparable to those in ILP studies in younger STS patients. ${ }^{1}$ In melanoma patients, the locally advanced bulky tumors, in particular, may cause such pain, hemorrhage, or vascular compression that amputation of the affected limb sometimes has to be considered. ILP with TNF and melphalan is an effective method to achieve local tumor control and thereby is of great antimorbidity value. It is regarded as the treatment of choice in bulky cases of melanoma or treatment failures after ILP with melphalan alone. The 3 deaths reported in this series are the only 3 postoperative deaths that we encountered in the 306 patients treated with TNF-based ILP in Rotterdam between 1991 and 2001, and this reflects the risks that have been accepted in this patient population. Two patients had extensive cardiovascular disease. The third patient died from sepsis caused by the infection of a totally necrotic massive tumor, which was confirmed to be a histopathologic CR, in the upper leg after ILP. The fact that this rapid tumor had penetrated the skin and was ulcerating should have kept us from performing the perfusion, because there was no way that infection of this necrotic mass could have been prevented. The fact that the complications occurred after leakage-free ILPs further underlines the point that the complications were due to patient-specific risks and not to uncontrolled elements of the ILP. We want to emphasize, however, that adequate experience with the procedure and the status of reference centers for TNF-based ILP are a prerequisite to deal successfully with these patients.

This series of older patients with limb-threatening sarcomas or multiple in-transit melanoma metastases demonstrates the safe and efficient use of TNF-based ILP. It results in high response rates and, thereby, high limb-salvage rates and very good local tumor control rates in both the sarcoma and the melanoma patients. Older patients should be offered and not be withheld a TNF-based ILP for limb salvage.

\section{REFERENCES}

1. Creech O, Krementz E, Ryan E, Winblad J. Chemotherapy of cancer: regional perfusion utilising an extracorporeal circuit. Ann Surg 1958;148:616-32.

2. Benckhuijsen C, Kroon BBR, van Geel AN, et al. Regional perfusion treatment with melphalan for melanoma in a limb: an evaluation of drug kinetics. Eur J Surg Oncol 1988;14:157-63.

3. Krementz ET, Carter RD, Sutherland CM, Hutton I. Chemotherapy of sarcomas of the limbs by regional perfusion. Ann Surg 1977; 185:555-64.

4. Klaase JM, Kroon BBR, Benckhuysen C, Van Geel AN, AlbusLutter CE, Wieberdink J. Results of regional isolation perfusion with cytostatics in patients with soft tissue tumors of the extremities. Cancer 1989;64:616-21.

5. Eggermont AMM, Schraffordt Koops H, Lienard D, et al. Isolated limb perfusion with high-dose tumor necrosis factor-alpha in combination with interferon-gamma and melphalan for nonresectable extremity soft tissue sarcomas: a multicenter trial. J Clin Oncol 1996;14:2653-65.

6. Eggermont AMM, Schraffordt Koops H, Klausner JM, et al. Isolated limb perfusion with tumor necrosis factor and melphalan for limb salvage in 186 patients with locally advanced soft tissue extremity sarcomas. The cumulative multicenter European experience. Ann Surg 1996;224:756-64.

7. Lejeune FJ, Kroon BBR, Di Filippo F, et al. Isolated limb perfusion: the European experience. Surg Oncol Clin North Am 2001; 10:821-32.

8. Lienard D, Eggermont AMM, Schrafford Koops H, et al. Isolated limb perfusion with tumour necrosis factor-alpha and melphalan with or without interferon-gamma for the treatment of in-transit melanoma metastases: a multicentre randomized phase II study. Melanoma Res 1999;9:491-502.

9. Fraker DL, Alexander HR, Andrich M, et al. Palliation of regional symptoms of advanced extremity melanoma by isolated limb perfusion with melphalan and high-dose tumor necrosis factor. Cancer J Sci Am 1995;1:122.

10. Bartlett DL, Grace M, Alexander HR, Libutti SK, Fraker DL. Isolated limb perfusion with tumor necrosis factor and melphalan in patients with extremity melanoma after failure of isolated limb perfusion with chemotherapeutics. Cancer 1997;80:2084-90.

11. Hashimoto H. Incidence of soft tissue sarcomas in adults. Curr Top Pathol 1995;89:1-16.

12. Hall HI, Miller DR, Rogers JD, Bewerse B. Update on the incidence and mortality from melanoma in the United States. $J \mathrm{Am}$ Acad Dermatol 1999;40:35-42.

13. Vrouenraets BC, Kroon BB, Ogilvie AC, et al. Absence of severe systemic toxicity after leakage-controlled isolated limb perfusion with tumor necrosis factor-alpha and melphalan. Ann Surg Oncol 1999;6:405-12.

14. Stam TC, Swaak AJ, de Vries MR, ten Hagen TL, Eggermont AM. Systemic toxicity and cytokine/acute phase protein levels in patients after isolated limb perfusion with tumor necrosis factor-alpha complicated by high leakage. Ann Surg Oncol 2000;7:268-75.

15. Klaase JM, Kroon BB, van Geel AN, Eggermont AM, Franklin HR. Systemic leakage during isolated limb perfusion for melanoma. Br J Surg 1993;80:1124-6.

16. Wieberdink J, Benckhuysen C, Braat RP, van Slooten EA, Olthuis GA. Dosimetry in isolation perfusion of the limbs by assessment of perfused tissue volume and grading of toxic tissue reactions. Eur $J$ Cancer Clin Oncol 1982;18:905-10.

17. Eggermont AMM, Schraffordt Koops H, Lienard D, Lejeune FJ, Oukerk M. Angiographic observations before and after high dose TNF isolated limb perfusion in patients with extremity soft tissue sarcomas. Eur J Surg Oncol 1994;20:323-4.

18. De Wilt JHW, ten Hagen TLM, de Boeck G, van Tiel ST, de Bruijn EA, Eggermont AMM. Tumour necrosis factor alpha increases melphalan concentration in tumour tissue after isolated limb perfusion. Br J Cancer 2000;82:1000-3.

19. van der Veen AH, de Wilt JHW, Eggermont AMM, van Tiel ST, ten Hagen TLM. TNF- $\alpha$ augments intratumoural concentration of doxorubicin in TNF- $\alpha$-based isolated limb perfusion in rat sarcoma models and enhances antitumour effects. Br J Cancer 2000;82: 973-80.

20. Vrouenraets BC, Eggermont AMM, Hart AA, et al. Regional toxicity after isolated limb perfusion with melphalan and tumour necrosis factor-alpha versus toxicity after melphalan alone. Eur J Surg Oncol 2001;27:390-5. 